\title{
A cromatografia líquida moderna e a espectrometria de massas: Finalmente "compatíveis"? II. A escolha do analisador de massas
}

\author{
Fernando M. Lanças \\ Instituto de Química de São Carlos, Universidade de São Paulo - USP, Cep 13560-970, São Carlos, SP, Brasil \\ e-mail: flancas@iqsc.usp.br
}

Resumo

A cromatografia líquida de alta eficiência (HPLC ou CLAE) é uma das principais técnicas utilizadas na análise de compostos não voláteis e/ou termicamente instáveis. Apesar de ser uma excelente técnica de separação, a HPLC necessita de uma técnica confirmatória quando a análise qualitativa (confirmação da identidade química) é também necessária. Dentre as várias opções existentes no momento, a espectrometria de massas (ms) é a técnica que melhor fornece as informações estruturais necessárias. O acoplamento entre estas duas técnicas dá origem a uma ferramenta analítica versátil e de grande potencial na análise qualitativa e quantitativa: a LC/MS (cromatografia líquida acoplada à espectrometria de massas). O presente artigo, segundo de uma série sobre o tema, apresenta de forma crítica e detalhada a escolha do analisar de massas para LC-MS(MS).

Palavras-chave

Cromatografia líquida; HPLC; CLAE; Espectrometria de massas; LC-MS/MS.

\section{Modern liquid chromatography and mass spectrometry: Finaly compatible? II. Selecting the mass analyzer}

\section{Abstract}

High Performance Liquid Chromatography (HPLC) is one of the most utilized analytical techniques for determination of nonvolatile and thermally unstable compounds. Although being an excellent separation technique, HPLC requires a confirmatory technique when qualitative analysis is being performed. Amongst the several available complimentary techniques, Mass Spectrometry is the one that supplies the structural information required to complement the HPLC separation; by coupling these two techniques, a powerful tool become available for qualitative and quantitative analysis: LC/MS (Liquid Chromatography-Mass Spectrometry). This paper, the second one in a series, presents a critical and detailed discussion on the proper selection of the ion analyzer for LC-MS(MS).

Keywords

Liquid Chromatography; HPLC; CLAE; Mass Spectrometry; LC/MS. 


\section{Introdução}

Em um artigo anterior desta série $e^{[1]}$ o autor descreveu os principais aspectos envolvidos no acoplamento entre cromatografia líquida moderna e a espectrometria de massas (LCMS), com ênfase na instrumentação adequada para contornar as dificuldades apresentadas pela incompatibilidade entre os aspectos operacionais existentes entre essas técnicas. Neste segundo trabalho da série serão discutidos os vários aspectos práticos envolvidos na escolha do analisador de íons mais adequado para LC-MS e LC-MS/MS, a partir das necessidades requeridas pelo tipo de experimento a ser realizado e dos resultados esperados.

A Figura 1 ilustra, de forma esquemática, os principais componentes de um espectrômetro de massas típico.

A amostra a ser analisada é introduzida no espectrômetro de massas através de um inlet (dispositivo para a introdução da amostra no espectrômetro) e direcionada para a fonte de ionização. Nos estágios iniciais do desenvolvimento da técnica, a amostra era introduzida pela vaporização direta dela; com o desenvolvimento

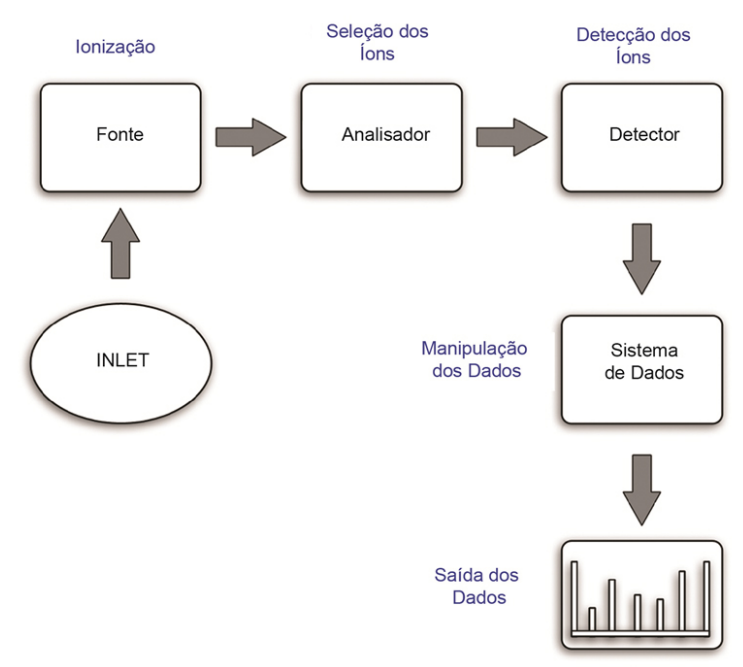

Figura 1 Esquema genérico das principais partes de um espectrômetro de massas ${ }^{[1]}$. das técnicas cromatográficas tornou-se bastante comum o uso de um cromatógrafo como fonte de introdução da amostra no MS. Nesse último caso, os picos cromatográficos gerados pela separação dos componentes da amostra são individualmente introduzidos na fonte de ionização do MS para gerar os íons a serem posteriormente separados no analisador e encaminhados para detecção e quantificação. Um software apropriado instalado em um computador efetua os cálculos, gera os espectros de massas a serem impressos e comanda as funções do espectrômetro.

Dentre os principais componentes de um espectrômetro de massas (MS), o analisador de massas possui relevância particular pelo fato de ser o responsável pela seleção e/ou separação (ou ausência dela) dos íons, de acordo com a relação existente entre suas massas (m) e cargas (e), ou seja, a razão m/e de cada íon. As características de construção e operação diferem de um analisador para outro, assim como seus benefícios e limitações. Uma vez que existe hoje uma grande diversidade de analisadores de massas, a escolha do mais apropriado deve ser efetuada considerando-se a aplicação (p. ex., faixa de massas desejada), desempenho (p. ex., resolução de massas) e custo. Em função desses fatores, não existe um analisador de massas que seja ideal para todas as aplicações, conforme descrito há décadas por Brunnee ${ }^{[2]}$.

Apesar dos analisadores de massas poderem ser classificados de acordo com diferentes critérios, o mais comum tem sido classificá-los com base na resolução e exatidão de massas, enfoque que será utilizado no presente trabalho.

\section{Analisadores de massas}

O efluente da coluna de cromatografia líquida, após ser ionizado - geralmente à pressão atmosférica (API), por um dos processos descri- 
tos em detalhes no artigo anterior ${ }^{[1]}$ desta série (ESI, APCI ou APPI) -, é direcionado para o analisador de massas. Os analisadores de massas separam os íons de acordo com a relação existente entre suas massas e cargas $(\mathrm{m} / \mathrm{z})$ podendo usar diferentes princípios de construção e de operação. Discutem-se, a seguir, os principais aspectos dos analisadores de interesse no enfoque deste artigo. Mais detalhes a respeito, especialmente a teoria física e matemática para cada um deles, podem ser encontrados em artigo anterior desta série ${ }^{[1]}$.

\subsection{Analisadores de massas baseados em setores elétricos e magnéticos}

Nos estudos experimentais sobre a natureza dos "raios catódicos" (elétrons), J. J. Thomson aplicou campos magnéticos e elétricos a um feixe de elétrons, obtendo uma estimativa da razão $\mathrm{m} / \mathrm{e}$ para esse feixe ${ }^{[3]}$. O equipamento utilizado é considerado como o precursor dos espectrômetros de massas modernos, muitos dos quais ainda utilizam os mesmos princípios, com pequenas modificações tecnológicas.

Em um espectrômetro de massas de deflexão magnética, os íons, ao deixarem a fonte, são acelerados a uma velocidade alta, passando por um setor magnético no qual um campo magnético é aplicado em direção perpendicular à da direção do movimento do íon. Quando uma aceleração é aplicada perpendicularmente à direção de movimento de um objeto qualquer, sua velocidade permanece constante e o objeto viaja em um caminho circular. Assim, o setor magnético segue um arco; o raio e o ângulo do arco variam de acordo com os detalhes de construção. Um setor magnético sozinho irá separar íons de acordo com a razão massa/carga; entretanto, a resolução nesse caso será limitada pelo fato de que os íons saindo da fonte não terão exatamente a mesma energia e, portanto, não terão exatamente a mesma velocidade. Para melhorar a resolução, adiciona-se um setor elétrico que focaliza os íons de acordo com suas energias cinéticas. O formato será o mesmo do campo magnético, ou seja, em arco, uma vez que se aplicará uma força perpendicular à direção do movimento do campo.

Nos espectrômetros denominados equipamentos "de setores", dois tipos de princípios físicos (campos associados aos setores) são empregados: magnético (B) e elétrico (E). O movimento de um íon em um campo magnético $B$ e as equações matemáticas que o descrevem foram discutidos em detalhes em artigo anterior ${ }^{[1]}$.

A Figura 2 ilustra um espectrômetro de massas denominado de duplo foco ou duplo setor (magnético e elétrico). Espectrômetros desse tipo são capazes de operar em resoluções maiores (frequentemente acima de 10.000) na determinação de massas superiores a $15.000 \mathrm{Da}$, com exatidão de massas elevada. $\mathrm{Na}$ prática, esses parâmetros podem ser ampliados para valores ainda melhores, diminuindo-se a voltagem aplicada e estreitando-se as fendas. Porém, isto ocorrerá à custa de uma diminuição significativa da sensibilidade. Uma diminuição no espalhamento de íons e melhora na transmissão deles pode ser conseguida operando-se a fonte de íons em valores elevados (superiores a $8.000 \mathrm{~V}$ ), o que cria uma dificuldade para o acoplamento LC-MS empregando electrospray (ESI) como modo de ionização, devido à formação de arco voltaico pela elevada voltagem e pelas pressões relativamente altas. Esse problema tem sido corrigido em instrumentos de geração mais atual. Como ocorre com qualquer outro equipamento, esses instrumentos apresentam vantagens e limitações, dependendo da aplicação e dos recursos financeiros disponíveis.

As principais vantagens apresentadas pelos equipamentos que utilizam setores elétrico e magnético como analisadores de íons são a alta 


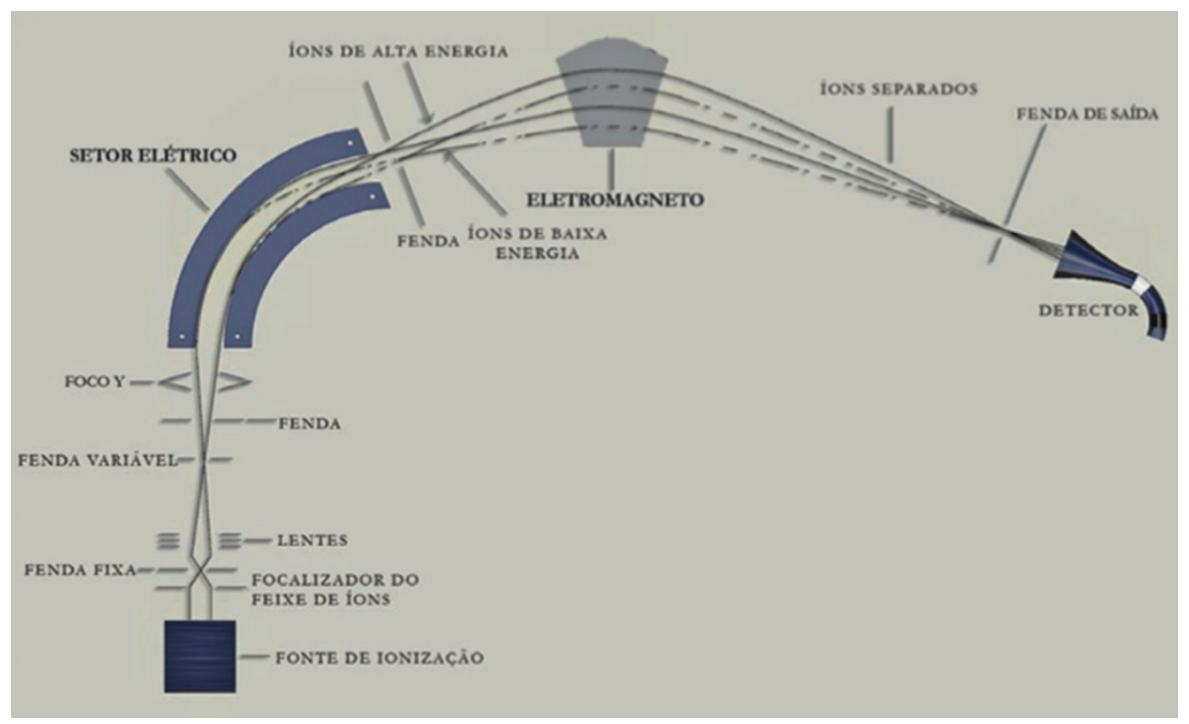

Figura 2 Esquema simplificado de um espectrômetro de massas de duplo foco ou duplo setor (elétrico, E; e magnético, B).

resolução e exatidão de massas. As principais limitações são o elevado custo e complexidade (tanto na aquisição e operação, quanto na manutenção), velocidade limitada de varredura, sensibilidade baixa quando operado em resoluções elevadas, potenciais problemas no acoplamento com LC-ESI, devido à formação de arco voltaico. Em função dessas características, e das limitações apresentadas, esse tipo de instrumento, atualmente, é mais empregado em medidas de massas com alta resolução e em estudos básicos em MS, tais como estudos de fragmentação, do que no acoplamento LC-MS.

\subsection{Analisadores de massas do tipo quadrupolo}

O quadrupolo é o analisador de massas mais popular no momento devido, principalmente, à sua simplicidade, preço relativamente baixo, boa linearidade em análises quantitativas, facilidade de ser entendido e operado. Apesar de usualmente utilizado com resolução baixa (tipicamente $\mathrm{R}=1.000$ ), esta pode ser aumentada em condições favoráveis para valores superiores a 4.000. Sua exatidão de massas encontra-se, geral- mente, entre 0,1 e 0,2 unidades de massa atômica (u.m.a.; a.m.u.; u ou Dalton) e a faixa de massas, usualmente entre 10 e $4.000 \mathrm{Da}$.

O quadrupolo é composto de quatro barras, usualmente feitas de metal, dispostas em dois pares (Figura 3). Apesar de as barras com sessão de choque hiperbólico serem mais eficientes, por questões econômicas usualmente empregam-se barras cilíndricas. Um par de barras é mantido em um potencial elétrico positivo, enquanto que o outro, a um potencial negativo. Uma combinação de corrente contínua (DC) e radiofrequência (Rf) é aplicada nas barras. O par positivo de barras atuará como um filtro para massas mais elevadas, enquanto que o par negativo age como um filtro para massas pequenas. Os quadrupolos operam a uma resolução constante (a qual depende da razão $\mathrm{Rf} / \mathrm{DC}$ ), mantendo a razão Rf/DC constante. Considerando-se uma dada amplitude para as voltagens Rf e DC, somente os íons que apresentarem determinada razão massa/carga $(\mathrm{m} / \mathrm{z})$, que esteja em ressonância com o campo aplicado, irão passar pelas barras do quadrupolo e serão detectados. Os demais íons que entrarem no quadrupolo terão suas tra- 


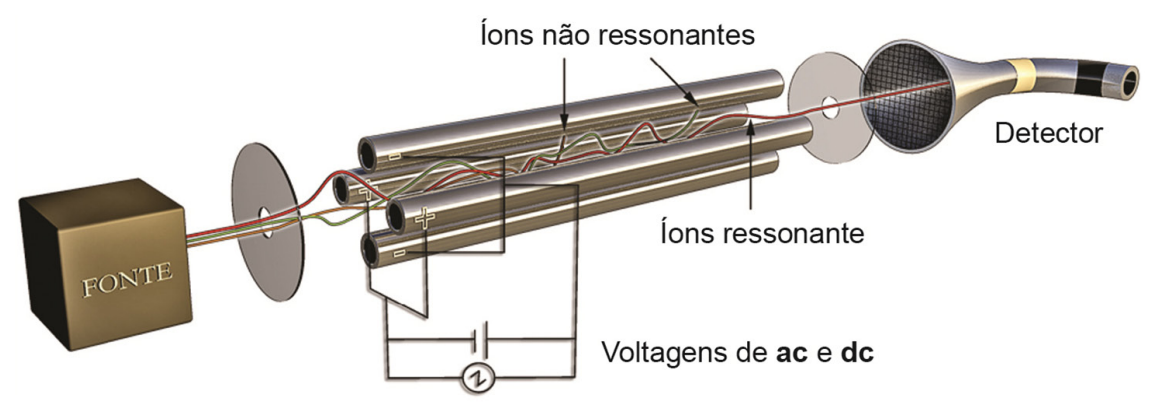

Figura 3 Esquema de um espectrômetro de massas típico evidenciando as quatro barras que constituem um analisador do tipo quadrupolo.

jetórias instáveis e, como consequência, atingirão as barras e serão eliminados pela bomba de vácuo.

Mantendo constante a razão $\mathrm{V}_{\mathrm{DC}} / \mathrm{V}_{\mathrm{RF}}$, um gráfico de a x q permite definir graficamente uma linha de estabilidade dos íons. Frequentemente, a razão $\mathrm{V}_{\mathrm{DC}} / \mathrm{V}_{\mathrm{RF}}$ é selecionada de maneira que uma janela de $1 \mathrm{Da}$ é escolhida, resultando em uma resolução unitária em toda a faixa de massa analisada.

\subsection{Analisadores de massas do tipo ion trap (aprisionadores de íons)}

Os analisadores do tipo ion trap (aprisionadores de íons) são também denominados de quadrupolos tridimensionais ou quadrupolos ion trap, enquanto que os quadrupolos descritos no item anterior são denominados simplesmente quadrupolos ou, alternativamente, quadrupolos lineares. Nos analisadores do tipo ion trap um eletrodo hiperbólico na forma de um anel (denominado ring electrode) é colocado entre dois eletrodos hiperbólicos denominados eletrodos end cap. Uma voltagem Rf (corrente alternada, $\mathrm{AC}$ ), de amplitude variável $\mathrm{V}$ e com frequência ao redor de $1 \mathrm{MHz}$, é aplicada ao ring electrode, enquanto que os eletrodos end cap são aterrados (Figura 4). Os dois eletrodos end cap apresentam um orifício no centro; o eletrodo superior permite a passagem dos íons provenientes da fonte

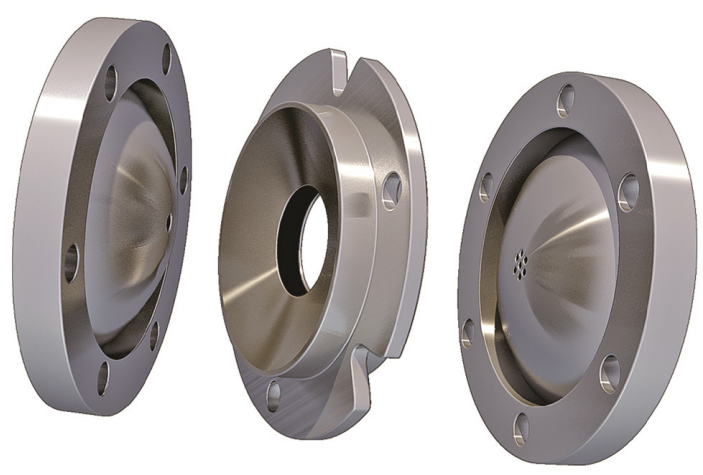

Figura 4 Eletrodos que formam a parte principal de um analisador do tipo ion trap. O eletrodo central é utilizado para aprisionar os íons, enquanto os outros dois servem um para focalizar a entrada dos íons provenientes da fonte de ionização no eletrodo central e o outro para focalizar a saída dos íons em direção ao detector.

de ionização (eletrodo de entrada) e os direciona para o ring electrode, enquanto que o orifício do eletrodo de saída serve para direcionar os íons ejetados para detecção. Nesse tipo de analisador normalmente não se aplica voltagem DC (corrente direta); apenas a Rf. Tipicamente, o filamento é ligado e os íons dentro da trap (armadilha), ali formados ou nele introduzidos - com um valor de $\mathrm{m} / \mathrm{z}$ acima de um limite estabelecido por V - serão aprisionados (trapped) por um tempo ao redor de $1 \mathrm{~ms}$ (milissegundo). O filamento é então desligado e uma varredura de $\mathrm{V}$ é executada para obter-se um espectro de massas. Os íons de razão massa/carga igual a m/z serão 
acelerados na direção do eixo $\mathrm{z}$ e ejetados pelo eletrodo end cap de saída dos íons sendo, então, detectados. As equações que descrevem o movimento dos íons do ion trap são similares às descritas para o quadrupolo linear.

Juntamente com o quadrupolo linear, o ion trap é um dos analisadores de íons mais populares no momento devido a seu custo relativamente baixo (o qual é, grosso modo, comparável ao de um quadrupolo) e pequeno tamanho, podendo ser utilizado na obtenção de analisadores que ocupam pouco espaço. Sua resolução é similar à do quadrupolo linear (unitária), podendo ser aumentada empregando-se varreduras mais lentas em uma faixa de massas menores. Nessas condições, resoluções próximas de 5.000 podem ser obtidas. As aplicações típicas desse analisador são similares àquelas do quadrupolo.

\subsection{Analisadores de massas do tipo Time-of-Flight (ToF - tempo de vôo)}

Apesar de ser geralmente aceito que o conceito do analisar do tipo ToF foi desenvolvido por William Stephens ${ }^{[4,5]}$, na Universidade da Pensilvânia (USA), em torno de 1946, foram William Wiley e I. H. McLaren, da empresa Bendix (USA), os pioneiros a desenvolverem e comercializarem um equipamento desse tipo, no final de $1955^{[6]}$.

Em um sistema do tipo ToF, os íons formados na fonte de ionização são extraídos e acelerados a alta velocidade por um campo elétrico em um tubo longo (drift tube), após o qual atingem o detector. A velocidade alcançada pelo íon acelerado é proporcional à raiz quadrada de sua razão $\mathrm{m} / \mathrm{z}$ - por simplicidade, assume-se ser inversamente proporcional à massa. De forma análoga, o tempo necessário para um íon atravessar o tubo será inversamente proporcional à raiz quadrada da razão $\mathrm{m} / \mathrm{z}$ (também por simplicidade é comum assumir-se que é proporcional à massa), uma vez que a distância entre a formação do íon e o detector é fixa (depende do comprimento do tubo).

O princípio de operação do ToF baseia-se na medida do "tempo de voo" de um íon dentro do espectrômetro de massas. Uma vez que as dimensões do tubo e a energia cinética dos íons são bem conhecidas, o cálculo da razão $\mathrm{m} / \mathrm{z}$ torna-se simples ${ }^{[1]}$.

O desenvolvimento de um refletor (também conhecido como espelho de íons ou espelho eletrônico) e o uso de técnicas ortogonais de introdução dos íons (o-ToF) contribuíram para a melhora da resolução, por meio de um aprimoramento no controle ou compensação do espalhamento inicial de energia, e na distribuição espacial dos íons (maiores detalhes na referência 1).

$\mathrm{O}$ reflectron (tipo de ToF que utiliza um refletor no tubo de voo) proposto pelo pesquisador russo Boris A. Mamyrin ${ }^{[7,8]}$ utiliza um campo elétrico aplicado a uma série de grades ou eletrodos (também denominados pratos ou discos) para reverter a direção da trajetória dos íons que nele entram. Por meio desse dispositivo, os íons de mesma razão $\mathrm{m} / \mathrm{z}$ chegam ao mesmo tempo no detector, ainda que apresentem diferenças em sua energia cinética.

A Figura 5 ilustra o esquema genérico de um analisador do tipo ToF com refletor. A parte a da figura mostra um íon formado na fonte sendo acelerado no tubo em direção ao detector, sem ajuda do reflectron. Na parte b da mesma figura, o reflectron é ligado, observando-se que a trajetória do íon agora será curva, a dispersão dos íons de mesma razão $\mathrm{m} / \mathrm{z}$ é diminuída e a resolução aumentada, e os íons retornam ao drift tube antes de serem detectados.

Vários desenvolvimentos conduziram a refletores modernos com elevado desempenho ${ }^{[9-11]}$, com considerável redução no tamanho 

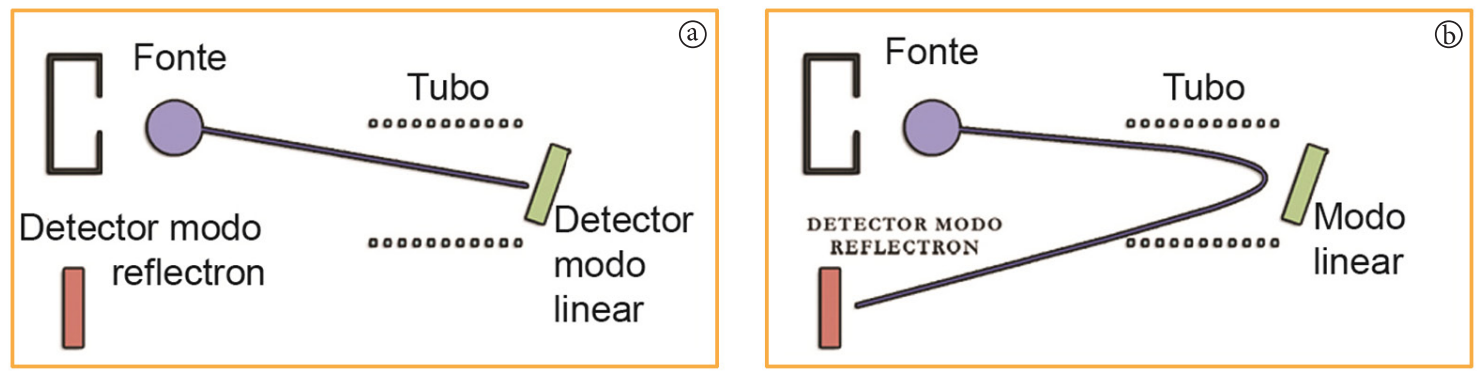

Figura 5 Esquema simplificado de um ToF com o reflectron fora de operação (a) e em operação (b), ilustrando a curva na trajetória dos íons provocada pelo refletor.

do equipamento e melhora da focalização dos íons, sendo amplamente empregados nos analisadores do tipo ToF mais modernos ${ }^{[1]}$.

Além do uso do reflectron, outra forma de aumentar a resolução utilizando analisador do tipo ToF é com o uso de geometria ortogonal (o-ToF). Nesse sistema os íons são produzidos de forma contínua na fonte de ionização (electrospray, por exemplo), acelerados e focalizados com ajuda de lentes apropriadas. A seguir, aplica-se uma aceleração pulsada ortogonal (perpendicular) ao movimento dos íons (oa, ortogonal acelleration), os quais irão adquirir velocidades as quais são independentes das velocidades adquiridas por sua aceleração na fonte.

O desempenho do oa-ToF (ToF com aceleração ortogonal) pode ser ainda melhorado com a adição de um gás. Esse colide com os íons em um guia de vários polos (usualmente, um quadrupolo ou hexapolo operando apenas com radiofrequência - modo $r$-only), diminuindo a energia ("resfriando") dos íons antes de eles entrarem na região de aceleração ortogonal, também denominada pulser, resultando na focalização dos íons em um feixe de diâmetro menor. $\mathrm{Na}$ região de alto vácuo situada antes do pulser, um conjunto de lentes eletrostáticas torna o feixe de íons paralelo, minimizando problemas de divergência na direção de aceleração. A combinação desses sistemas - aceleração ortogonal e resfria- mento por colisão com gás, juntamente com o reflectron, aumentaram a resolução dos atuais ToF-MS sem diminuir sua sensibilidade.

A Figura 6 ilustra o esquema de um ToF-MS atual de alta resolução, com aceleração ortogonal e reflectron. Os hexapolos e quadrupolos servem de guia para os íns no modo ToF, podendo ser utilizados para uma montagem em tandem (MS-MS) do tipo Q-ToF, empregando dois analisadores (quadrupolo-tempo de voo). Esses equipamentos possuem elevada resolução (no modo linear a resolução é limitada), boa sensibilidade, velocidade de varredura muito rápida (importante para picos cromatográficos estreitos). Porém exigem eletrônica bastante sofisticada, bom controle do tempo, da energia inicial e da distribuição espacial dos íons. Sua aplicação é bastante ampla, especialmente quando alta resolução é necessária. A faixa de massas que analisa é ampla (teoricamente ilimitada mas, na prática, massas muito elevadas - muito superiores a $500.000 \mathrm{Da}$ - são difíceis de serem determinadas com boa precisão e exatidão).

\subsubsection{Analisadores de massas baseados em transformada de Fourier (FT-MS)}

Apesar de existirem outros analisadores de massas para MS, os três descritos até o momento (quadrupolo, ion-trap e ToF) são, de longe, os mais empregados atualmente no acoplamento 


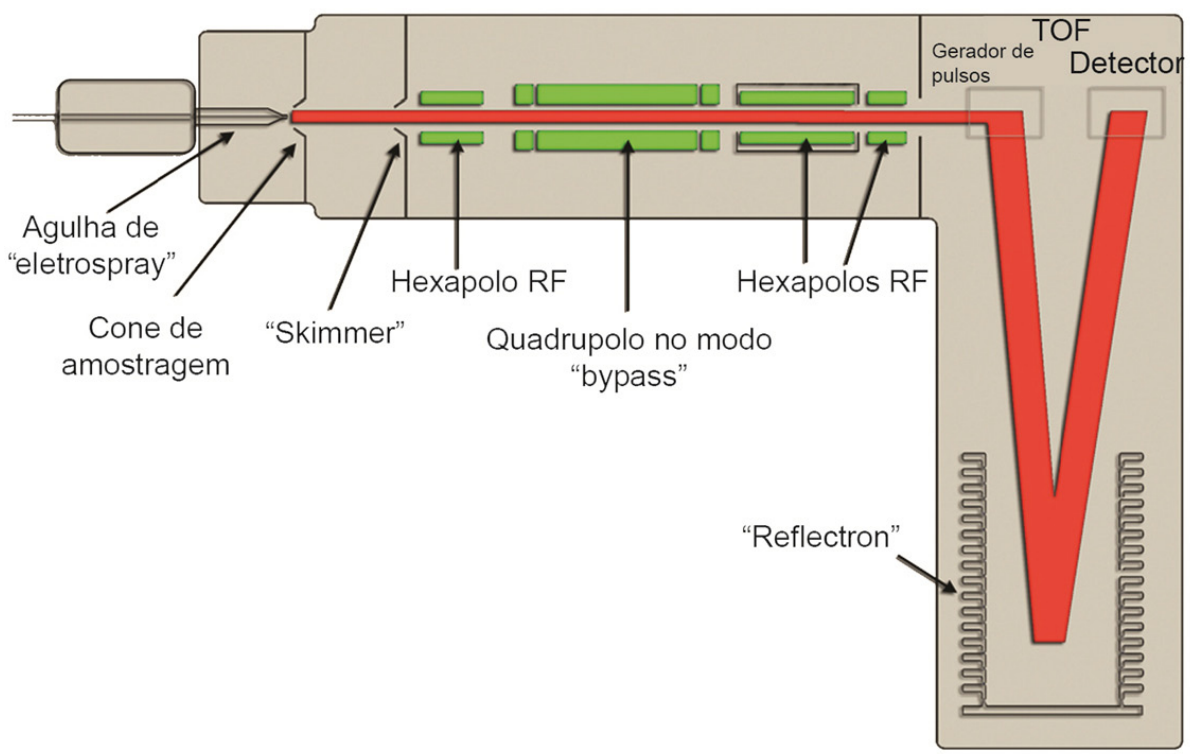

Figura 6 Analisador do tipo ToF com sistema de aceleração ortogonal (oa) e reflectron, podendo operar no modo LC-MS/MS na configuração Q-ToF (quadrupolo -ToF) ou no modo LC-ToF utilizando o quadrupolo apenas como filtro de massa, ao invés de analisador, ou seja, aplicando apenas radiofrequência, Rf (Rf-only mode).

LC-MS. Enquanto os dois primeiros são compactos, apresentam grande simplicidade, baixo custo e facilidade operacional, interpõem como principal limitação a baixa resolução. O ToF, por outro lado, perde para os dois analisadores nesses quesitos, mas apresenta resolução muito superior, principalmente no modo ao-TOF, característica necessária em análises que a requeiram.

Outro tipo de analisador de massas, disponibilizado para venda mais recentemente e de custo ainda acentuadamente elevado (porém com resolução igualmente superior aos três analisadores já discutidos), é o FTICR (Fourier Transform Ion Cyclotron Resonance ou Ressonância Ciclotrônica de Íons com Transformada de Fourier).

O FTICR-MS, também conhecido apenas como FT-MS, por ter sido o primeiro equipamento do tipo a ser comercializado, foi desenvolvido por Mel Comisarow e Alan G. Marshall, na Universidade de British Columbia,
Canadá, em $1974^{[12]}$. Os fundamentos da técnica baseiam-se no uso da Ressonância de Íons em Ciclotron - Espectrometria de Massas (ICR-MS), de estudo publicado por Hipple, em $1949^{[13]}$, e na existência do fenômeno bem estabelecido e conhecido do uso de Transformada de Fourier em Ressonância Magnética Nuclear (FT-NMR).

Em FTICR-MS, os íons gerados na fonte passam por uma série de estágios de diminuição de pressão em direção a um alto vácuo. Ao entrarem na cela, em que serão aprisionados (ion trap), a temperatura estará próxima ao zero absoluto e a pressão ao redor de $10^{-8}$ bar. Isso é conseguido mantendo-se a cela dentro de um supercondutor de alto campo magnético (geralmente entre 4,7 e 13 Tesla, valores esses que têm sido aumentados rapidamente), o qual é resfriado pelo emprego de nitrogênio e hélio, ambos no estado líquido. Ao passarem pelo campo magnético $B$, os íons terão sua trajetória descrita por um movimento circular em um plano perpendicular ao do campo 
(Figura 7). Os íons não são expulsos da cela graças a uma pequena voltagem (corrente contínua) aplicada aos eletrodos de aprisionamento (trapping electrodes), a qual gera um campo elétrico $\mathrm{E}$ perpendicular ao campo magnético B.

A frequência de rotação de um íon no cíclotron $(\omega c)$ depende de sua massa $(m)$ e carga (z). No início do experimento, nenhum sinal é observado, pois o raio do movimento é muito pequeno. Varrendo-se a radiofrequência RF pulsada pelas placas de excitação da cela, é possível excitar-se cada íon com razão m/z. Cada frequência de excitação entra em ressonância com determinado íon e o excita para órbitas maiores, onde induz uma corrente alternada entre as placas do detector (Figura 8). A corrente induzida tem a mesma frequência de ciclotron dos íon, e intensidade proporcional a seu número. Quando a frequência sai de ressonância para uma dada razão $\mathrm{m} / \mathrm{z}$, os íons retornam ao estado primitivo e outro pacote de íons com a próxima razão $\mathrm{m} / \mathrm{z}$ será excitado e dessa forma o processo continua. Para efeito prático, entretanto, consideram-se as frequências como simultâneas, resultando em espectros complexos da variação da frequência com o tempo. Esse sinal complexo gerado sofrerá deconvolução por meio de métodos, empregando-se Transformada de Fourier ${ }^{[14]}$, resultando em espectros que apresentam a variação de intensidade em função da frequência $\omega c$.

O FT-ICR-MS é atualmente o tipo de analisador de massas para uso acoplado com LC que apresenta a maior resolução (superior a $10^{6}$, ou seja, quase ilimitada). Entretanto, seu custo ainda é elevado, possuindo uma tecnologia bastante mais complexa que os demais analisadores descritos, especialmente em relação ao alto vácuo necessário. Sua principal aplicação, no momento, é em estudos onde uma resolução extremamente elevada é necessária, ou para estudos fundamentais de fragmentação de moléculas.

Outro tipo de analisador de massas que também utiliza Transformada de Fourier (FT) é o orbitrap, cujas raízes remontam a 1923, quando Kingdon ${ }^{[15]}$ propôs o princípio do aprisionamento orbital (orbital trapping). Os estudos subsequentes demonstraram que partículas carregadas podiam ser aprisionadas em cam-

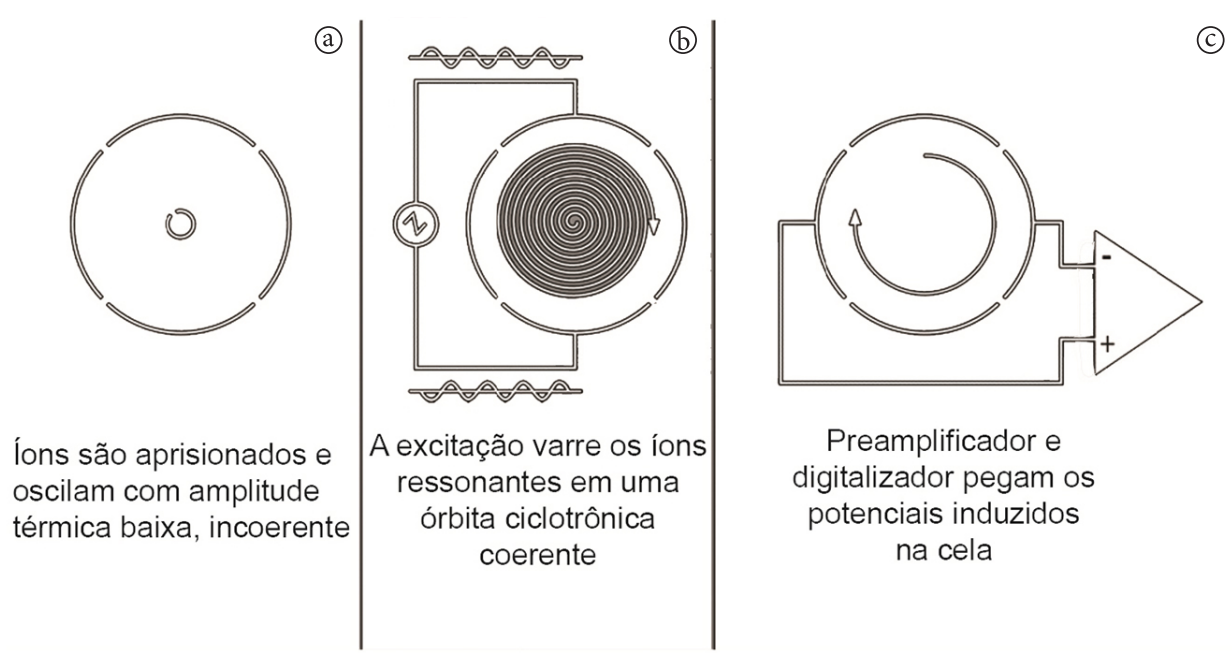

Figura 7 Movimento de um íon antes e depois do processo de excitação, mostrando a órbita ciclotrônica percorrida. Em a, os íons aprisionados oscilam com amplitude térmica baixa, incoerente; em b, a excitação varre os íons em órbita eletrônica coerente; em c, um pré-amplificador e um digitalizador pegam os potenciais induzidos na cela. 


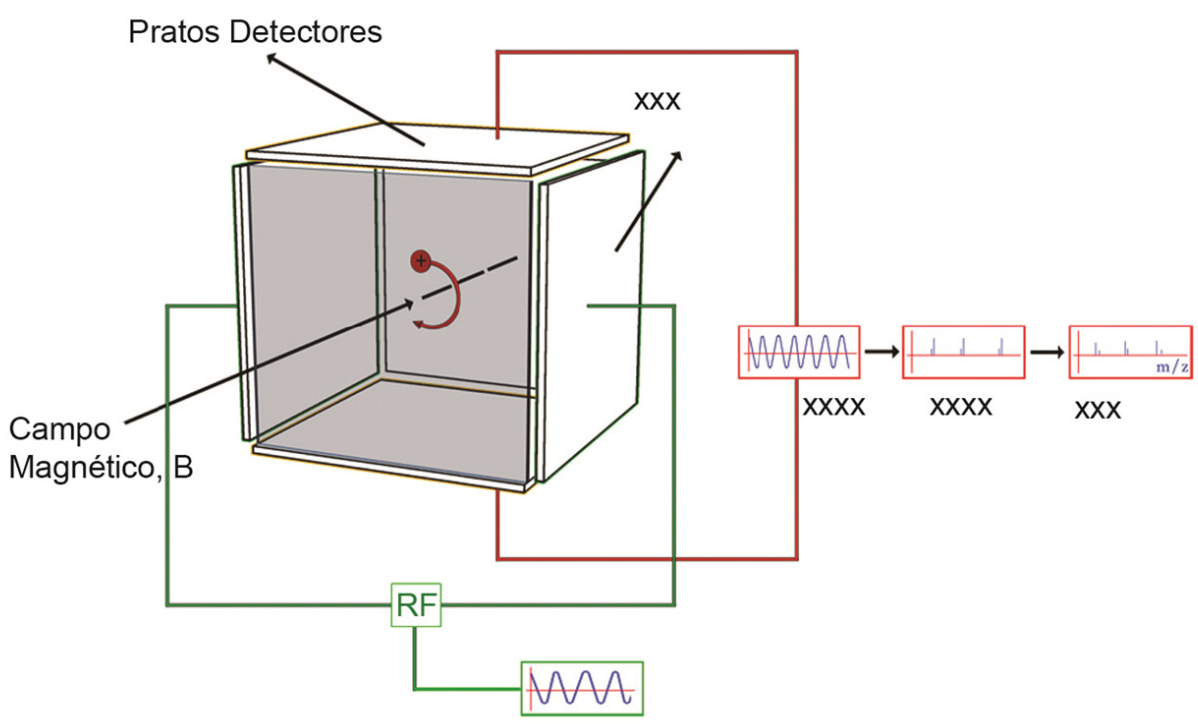

Figura 8 Esquema simplificado de um sistema FT-ICR-MS ilustrando a detecção e geração de sinal via aprisionamento de íons (ion trap) e o posterior tratamento do sinal através de Transformada de Fourier (FT) para gerar o espectro de massas.

pos eletrostáticos, mas não foi discutido como isso poderia ser utilizado em análises de massas. O posterior desenvolvimento no campo de óptica de partículas carregadas permitiu avanços importantes no aprimoramento da área de campos eletrostáticos ${ }^{[16]}$. Knight, em 1981, relatou os resultados de análises de massas efetuados através da aplicação de excitação ressonante axial a íons aprisionados produzidos por laser ${ }^{[17]}$. Os resultados mostraram que o eventual uso dessa ideia para produzir analisadores de íons iria requerer desenvolvimentos em praticamente todas as áreas, desde o campo aplicado até o sistema de detecção dos íons.

Esses avanços, que possibilitaram o desenvolvimento do orbitrap a um estágio de analisador de íons de alta resolução comercialmente disponível para espectrometria de massas a partir de 2005, ocorreram a partir dos trabalhos pioneiros de Makarov ${ }^{[18,19]}$.

A Figura 9 ilustra o analisador de massas orbitrap, o qual consiste de um eletrodo externo similar a uma barra (a) e um eletrodo central (b) ao longo

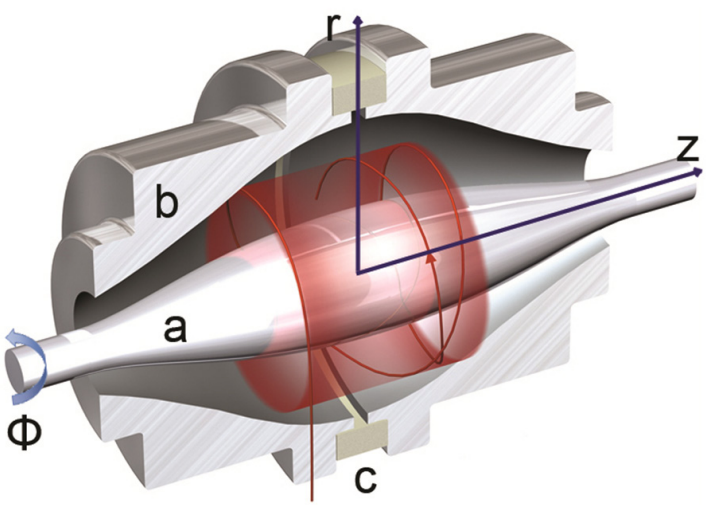

Figura 9 Desenho esquemático de um analisador de massas do tipo orbitrap; a, eletrodo externo em forma de barra; b, eletrodo central; r, z são coordenadas cilíndricas.

do eixo. $\mathrm{O}$ formato construtivo desses eletrodos permite produzir um potencial $U$ dado por:

$$
U(r, z)=\frac{k}{2}\left(z^{2}-\frac{r^{2}}{2}\right)+\frac{k}{2} \cdot(R m)^{2} \cdot \ln \left[\frac{r}{R m}\right]+C
$$

onde $\mathrm{r}, \mathrm{z}$ são as coordenadas cilíndricas $(\mathrm{z}=0$, sendo o plano de simetria do campo), C é uma constante, ké a curvatura do campo, Rm é carac- 
terístico do raio. Nesse trap, trajetórias estáveis combinam rotação ao longo do eletrodo central com oscilações ao longo do eixo, resultando em uma espiral bastante complexa, como proposto por Makarov ${ }^{[18,19]}$. As frequências de oscilação podem ser detectadas através da medida da corrente nos eletrodos externos do orbitrap ${ }^{[18,20-26]}$. Isso é seguido por uma Transformada de Fourier rápida para converter o sinal do domínio do tempo para um espectro massa-carga $(\mathrm{m} / \mathrm{z})$, de maneira similar ao que ocorre com o FT-ICR descrito anteriormente ${ }^{[1]}$.

\section{Resolução em espectrometria de massas}

Em cromatografia, a resolução (Rs) para um par de espécies químicas é usualmente definida como

$$
R s=\frac{t_{R 2}-t_{R 1}}{\left(w_{b_{2}}+w_{b_{1}}\right) / 2}
$$

onde $t_{\mathrm{R} 2}$ é o tempo de retenção da espécie mais retida e $t_{\mathrm{R} 1}$ o tempo de retenção da menos retida; $w_{2} b_{2} w_{1}$ representam a largura da base das duas espécies, respectivamente. Como a diferença $t_{R 2}-t_{R 1}$ representa a diferença entre o tempo de retenção da espécie 2 e o da espécie 1 , é comum usar-se $\Delta t_{\mathrm{R}}$ para representa-la; como a largura na base de dois picos adjacentes possui praticamente o mesmo valor, $\mathrm{wb}_{2}+\mathrm{wb}_{1}$ costuma ser representado por $2 \mathrm{wb}_{2}$. Substituindo-se esses valores na Equação 2, temos:

$$
R s=\frac{\Delta t}{2 w b_{2} / 2}=\frac{\Delta t}{w b_{2}}
$$

Ou seja, a resolução cromatográfica é dada pela relação entre $\Delta t$ (diferença dos tempos de retenção das duas espécies) e a largura na base delas. Assim, quanto maior a distância entre os picos e menor a largura na base deles, maior será a resolução e melhor a separação entre as espécies em análise.

Em espectrometria de massas a resolução para um par de íons pode ser definida de maneira similar à utilizada para as técnicas cromatográficas. Nesse caso é comum indicar-se a que percentagem da altura do pico, a partir da linha de base, a largura é medida. A Figura 10 ilustra medidas a partir de $5 \%$ e a partir de $10 \%$ da altura do pico, valores comumente adotados para esse tipo de medida.

Na Figura 10 dizemos que a resolução a 10\% do vale será, por exemplo, 10.000 se o pico de massa 10.000 se separar do pico de massa 10.001 com uma sobreposição (ou um vale sem resolução entre os picos) igual a $10 \%$ da altura dos picos de altura equivalente. De maneira geral, afirma-se que a resolução será igual a $\mathrm{M}$, medida em um vale de $10 \%$, quando um pico de massa M separar-se de outro de massa M+1 com uma sobreposição de 10\%. Para esse tipo de determinação são usados dois picos de massas subsequentes e de alturas similares.

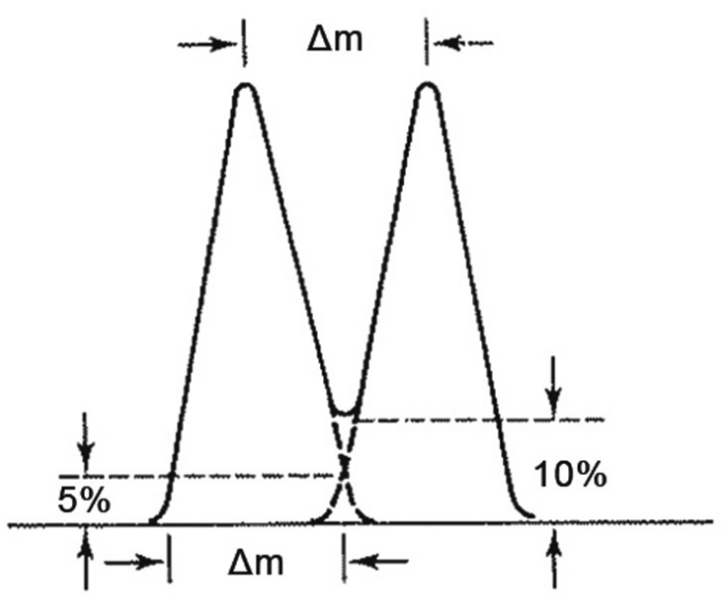

Figura 10 Medida da largura de um íon $(\Delta \mathrm{m})$ em espectrometria de massas, efetuada a $5 \%$ e a $10 \%$ da sua altura. 
Uma forma equivalente, e muitas vezes mais simples, de determinar a resolução é efetuar a medida em apenas um pico, podendo a medida ser efetuada a $5 \%, 10 \%$ ou $50 \%$ de sua altura (exemplo a 50\% na Figura 11).

No exemplo da Figura 11, a resolução será dada pela relação entre a massa $M$ do íon usado na medida e $\Delta \mathrm{M}$, a largura do pico a uma dada altura, a qual deve ser especificada. Ou seja,

$$
R=\frac{M}{\Delta M}
$$

Supondo que o valor da massa do íon da Figura 11 é $10.000(\mathrm{M}=10.000)$ e que a largura medida a $50 \%$ da altura do pico seja $1(\Delta \mathrm{M}=1)$, a resolução nesse caso será:

$$
R=\frac{M}{\Delta M}=\frac{10.000}{1}=10.000
$$

Quando a medida de $\Delta \mathrm{M}$ é efetuada na metade da altura do pico (50\%), a resolução tem sido também especificada como FWHM (Full Width at Half Maximum), ou seja, largura total medida na metade da altura. Essa definição tem sido bastante empregada atualmente, especialmente pelos fabricantes de equipamentos, sendo uma tendência a ser seguida para a determinação de resolução de espectrômetros de massas mais atuais.

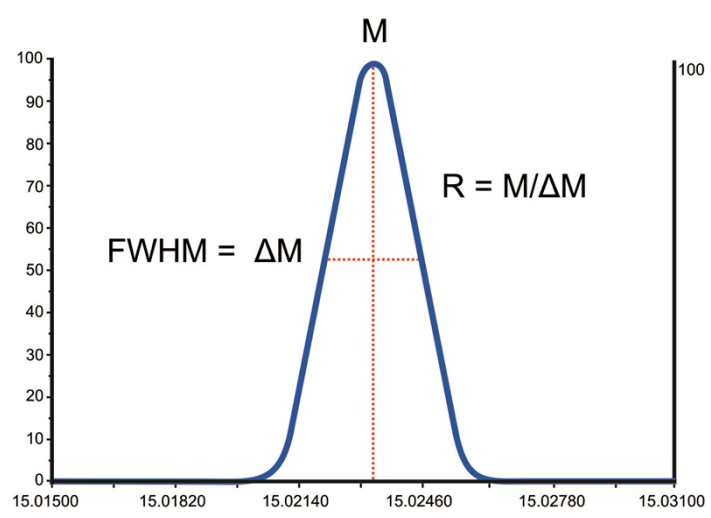

Figura 11 Determinação da resolução empregando apenas um pico, sendo a largura $\Delta \mathrm{m}$ medida a $50 \%$ de sua altura (FWHM).
Além dessas definições, mais comuns, existem algumas outras empregadas para a resolução, como a proposta por Karpas ${ }^{[27]}$ e também por Sparkman ${ }^{[28]}$, segundo os quais a resolução pode ser dada apenas pela diferença de massas entre os íons empregados na medida. Nesse caso,

$$
\mathrm{R}=\Delta \mathrm{m}=\mathrm{m}_{2}-\mathrm{m}_{1}
$$

Imaginando que o analisador separa um íon de m/z 101 do m/z 100, a resolução será:

$$
\mathrm{R}=\mathrm{m}_{2}-\mathrm{m}_{1=} 101-100=1
$$

Esse analisador teria resolução 1, também denominada de resolução unitária (típica dos quadrupolos mais antigos). Deve ser notado que, nesse caso, quanto menor a resolução, menor a separação das espécies, enquanto que, pela definição anterior, quanto maior a resolução, melhor a separação.

Qualquer que seja a definição adotada, essa deve ser informada, assim como as condições experimentais utilizadas na determinação, principalmente a razão m/z do(s) íon(s) envolvido(s).

Outro conceito similar ao da resolução ${ }^{[27,28]}$ e que tem sido amplamente utilizado, especialmente para especificação dos instrumentos pelos fabricantes, é o poder de resolução $\left(\mathrm{R}_{\mathrm{p}}\right)$, dado por:

$$
R=\frac{M}{\Delta M}
$$

$\mathrm{M}$ representa a massa e $\Delta \mathrm{m}$ a largura do pico empregado na medida. Deve ser especificado em que altura do pico a medida é realizada (geralmente isso é efetuado a $50 \%$ da altura, ou seja, FWHM).

Apesar de tanto o conceito de resolução quanto o de poder de resolução serem empregados em espectrometria de massas, é importante não confundi-los, pois numericamente são dife- 
rentes. O poder de resolução é usualmente um número grande e bastante utilizado como um parâmetro para medir o desempenho de um equipamento $^{[29]}$. A Tabela 1 ilustra o poder de resolução de alguns analisadores de massas mais comuns.

Publicações mais antigas - décadas de 1920 a 1940 - envolvendo alguns dos pioneiros da espectrometria de massas como Aston, Nier, Dempster, dentre outros, empregavam $\mathrm{R}$ como sendo o poder de resolução. Isso originou confusão entre os usuários da técnica durante muitos anos ${ }^{[30]}$, fazendo com que a ASMS (American Society for Mass Spectrometry) e a IUPAC (International Union for Pure and Applied Chemistry) se envolvessem na discussão dessa terminologia. Em 2013, a IUPAC elaborou um documento de recomendação a respeito das definições e terminologia em espectrometria de $\operatorname{massas}^{[31]}$.

De acordo com esta sugestão recente da IUPAC $^{[31]}$, a Resolução (R) em espectrometria de massas deve ser expressa como $\mathrm{m} / \Delta \mathrm{m}$, onde $\mathrm{m}$ é a massa do íon de interesse, $\Delta \mathrm{m}$ é sua largura (definida usando-se a largura do pico) ou o espaço entre dois picos de igual intensidade, com um vale entre eles inferior a $10 \%$ de sua altura (definido usando-se um vale de 10\%). O Poder

Tabela 1 Valores típicos do poder de resolução (FWHM) de alguns analisadores de íons mais comuns comercialmente disponíveis.

\begin{tabular}{lc}
\hline \multicolumn{1}{c}{ Tipo de analisador } & $\begin{array}{c}\text { Poder de resolução } \\
\text { (FWHM) típico* }\end{array}$ \\
\hline FT-ICR-MS & $>1.000 .000$ \\
FT-Orbitrap & 100.000 \\
Oa-ToF & $40.000-60.000$ \\
Quadrupolo/lon Trap** & 10.000 \\
Quadrupolo/lon Trap & 1.000 \\
\hline
\end{tabular}

*Variam de acordo com a marca, modelo e atualização; **Operando no modo ultrazoom. de Resolução (Rp) em espectrometria de massas é definido nesse documento como a habilidade de um instrumento ou procedimento de medida distinguir entre dois picos com valores $\mathrm{m} / \mathrm{z}$ diferindo por uma pequena quantidade e expresso como a largura do pico em unidades de massa. A IUPAC ainda define, no mesmo documento $^{[31]}$, poder de resolução de massas como sendo $\mathrm{m} / \Delta \mathrm{m}$, de forma similar à sua definição para resolução de massas. Embora não signifiquem a mesma coisa, e nem tenham o mesmo valor numérico, é muito comum empregar-se Resolução (R) e Poder de Resolução (Rp) como sinônimos em espectrometria de massas ${ }^{[32]}$.

A resolução em instrumentos do tipo setor magnético usualmente é definida com base em um vale de $10 \%$, que define $\Delta \mathrm{m}$ como a diferença de massas entre dois picos resolvidos com um vale de $10 \%$ entre eles ${ }^{[32]}$. As demais definições de resolução, usualmente, são medidas em um único pico ao invés de entre dois picos.

No caso de analisadores do tipo quadrupolo, ToF, Orbitrap e FTICR, a definição empregando $\Delta \mathrm{m}$ medido na metade da altura do pico (FWHM) é, usualmente, preferida. Entretanto, o valor mínimo de resolução quando se emprega FWHM é maior do que o valor obtido usando largura a $5 \%$ da altura ou então um vale de $10 \%$ (usualmente o dobro ou mais). Uma resolução de 30.000 obtida empregando-se FWHM é aproximadamente equivalente à resolução de 15.000 obtida empregando-se no cálculo a definição de um vale de $10 \%$.

Outro fator a ser considerado é que a resolução instrumental pode variar de acordo com a massa do íon. Em geral, nos casos dos quadrupolos, o valor aumenta linearmente com o aumento da massa e, no caso de ToF e instrumentos de duplo foco, o poder de resolução é mantido constante; no caso de FTICR e Orbitrap, ela diminui 
com o aumento da massa (no caso de FTICR, linearmente, e, no caso do Orbitrap, em função do quadrado da massa).

Assim, é importante, ao comparar-se a resolução de equipamentos de espectrometria de massas, levar em consideração vários fatores, inclusive se a medida é da Resolução de massas, do Poder de Resolução em espectrometria de massas ou do Poder de Resolução de massas. Além disso, deve-se definir claramente o critério utilizado (FWHM, largura a 5\% da altura ou vale de $10 \%$, por exemplo). Somente levando-se em consideração os vários fatores que interferem na determinação da resolução torna-se possível a comparação entre dois diferentes analisadores de íons.

\section{Exatidão de massas}

Os elementos químicos são formados por isótopos, ou seja, entidades químicas que possuem o mesmo número de prótons (mesmo número atômico, representado por $\mathrm{Z}$ ), porém diferentes números de nêutrons (e, portanto, diferentes massas atômicas, representadas por A). O elemento químico carbono, por exemplo, geralmente representado por ${ }_{6}^{12} \mathrm{C}$ é formado por três isótopos, todos com o mesmo número atômico - ou seja, com 6 prótons em seu núcleo - porém com diferentes números de nêutrons, resultando em diferentes números de massas: 12, 13, 14. O isótopo mais estável e mais abundante, com $\mathrm{A}=12$, apresenta 6 prótons e 6 nêutrons; o de massa intermediária, $A=13$, apresenta 6 prótons e 7 nêutrons; e o mais pesado, com $\mathrm{A}=14$, é instável e pouco abundante (devido ao número maior de nêutrons, o núcleo desse isótopo é instável, sendo radioativo). A Figura 12 ilustra a representação típica desses isótopos.
A fim de estabelecer um padrão de massas em uma escala atômica, geralmente denominada massa atômica ou peso atômico, foi escolhido o elemento químico carbono (geralmente referido como C-12) como padrão das massas. Nessa escala, uma unidade de massa atômica equivale a $1 / 12$ do ${ }^{12} \mathrm{C}$, ou seja, dividindo-se o átomo de carbono, assumindo-se apenas o isótopo 12 desse elemento, cada fração representa uma unidade de massa atômica (Figura 13).

De acordo com essa proposta, o elemento químico sódio, representado normalmente em química como ${ }^{23} \mathrm{Na}$ (ou seja, de massa atô-

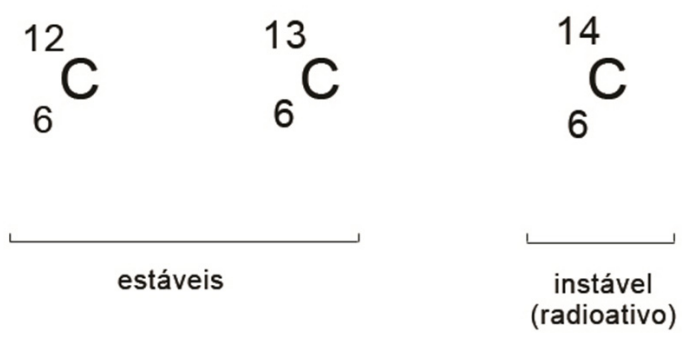

Figura 12 Isótopos do elemento químico carbono. Os isótopos 12 e 13 são estáveis e de grande utilidade em espectrometria de massas em geral, enquanto que o isótopo 14 é radioativo, pouco abundante e mais empregado em outras áreas.

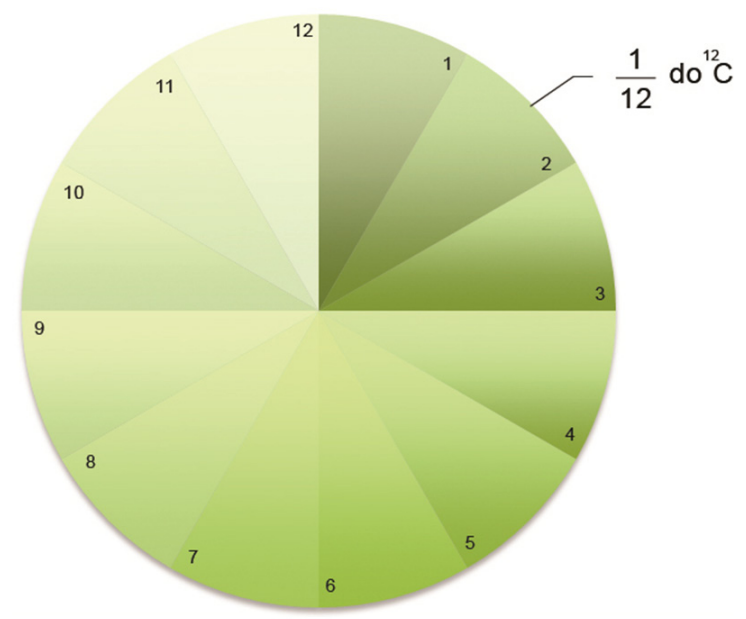

Figura 13 Definição da unidade de massa atômica (a.m.u., u.m.a. ou u.) como sendo 1/12 do isotópo 12 do carbono (C-12). 
mica 23) será 23 vezes mais pesado do que a unidade de massa atômica, ou seja, do que 1/12 do isótopo 12 do carbono.

A Tabela 2 ilustra a composição isotópica dos principais elementos químicos de interesse em espectrometria de massas e a abundância relativa das massas na formação dos elementos químicos.

Assim, o elemento químico hidrogênio $(\mathrm{H})$ é formado por 3 isótopos, sendo ${ }^{1} \mathrm{H}$ (abundância 99,985\%) e ${ }^{2} \mathrm{H}$ (abundância 0,015\%) estáveis e o ${ }^{3} \mathrm{H}$ radioativo e muito pouco abundante, de ocorrência considerada até o momento como próxima de zero e, consequentemente, irrelevante para a espectrometria de massas. Dessa forma, a massa atômica do elemento químico hidrogênio levará em conta a massa de cada isótopo e sua abundância isotópica, resultando em valores fracionários e não inteiros como usualmente.

Conforme discutido por Siuzdak ${ }^{[33]}$, o espectro de massas mede massas isotópicas e não massa molecular média (MW). Seja uma molécula constituída por 60 átomos de carbono, 122 de hidrogênio, 20 de nitrogênio, 16 de oxigênio e 2 de enxofre $\left(\mathrm{C}_{60} \mathrm{H}_{122} \mathrm{~N}_{20} \mathrm{O}_{16} \mathrm{~S}_{2}\right)$. A massa molecular (massa nominal) será obtida multiplicando-se o número de átomos de cada elemento pela massa integral do isótopo mais abundante e somando-se as contribuições de cada um (Tabela 3).

De acordo com esse raciocínio, a massa nominal dessa molécula, considerando-se apenas a massa inteira dos isótopos mais abundantes dos elementos que a compõem será 1.442 . Entretanto, a massa monoisotópica, considerando-se a massa exata (e não a massa inteira) dos isótopos mais abundantes será 1.442,8788; e a massa molecular média, considerando-se a média ponderada dos isótopos, será 1.443,8857. A massa monoisotópica ou massa exata é calculada considerando-se as massas disponíveis dos isótopos e, por isso, deveria ser denominada massa exata calculada (calculated exact

Tabela 2 Composição isotópica dos principais elementos químicos de interesse em espectrometria de massas (apenas os isótopos estáveis estão listados) ${ }^{[34]}$.

\begin{tabular}{ccccccc}
\hline \multirow{2}{*}{ Elemento } & \multicolumn{2}{c}{ Isótopo A } & \multicolumn{2}{c}{ Isótopo A+1** } & \multicolumn{2}{c}{ Isótopo A+2** } \\
\cline { 2 - 6 } & Massa & $\%^{*}$ & Massa & $\%$ & Massa & $\%$ \\
\hline $\mathrm{H}$ & 1 & 100 & 2 & 0,015 & $*$ & $*$ \\
$\mathrm{C}$ & 12 & 100 & 13 & 1,1 & $*$ & $*$ \\
$\mathrm{~N}$ & 14 & 100 & 15 & 0,37 & $*$ & $*$ \\
$\mathrm{O}$ & 16 & 100 & 17 & 0,04 & 18 & 0,20 \\
$\mathrm{~F}$ & 19 & 100 & $* *$ & $* *$ & $*$ & $*$ \\
$\mathrm{Si}$ & 28 & 100 & 29 & 5,1 & 30 & 3,4 \\
$\mathrm{P}$ & 31 & 100 & $*$ & $* *$ & $*$ & $*$ \\
$\mathrm{~S}$ & 32 & 100 & 33 & 0,80 & 34 & 4,4 \\
$\mathrm{Cl}$ & 35 & 100 & $*$ & $* *$ & 37 & 32,5 \\
$\mathrm{Br}$ & 79 & 100 & $*$ & $*$ & 81 & 98.0 \\
$\mathrm{I}$ & 127 & 100 & $*$ & $*$ & $*$ & $*$ \\
\hline
\end{tabular}

*Por convenção, os espectros de massas são normalizados de forma que o pico mais intenso tenha uma abundância de $100 \%$ e as abundâncias dos demais sejam calculadas em relação à abundância dele; **Alguns elementos químicos não possuem isótopos mais pesados $(A+1$ ou $A+2)$. 


\begin{tabular}{|c|c|c|c|}
\hline Elemento & $\begin{array}{c}\text { Número de } \\
\text { átomos na } \\
\text { molécula }\end{array}$ & $\begin{array}{l}\text { Massa do } \\
\text { isótopo mais } \\
\text { estável }\end{array}$ & Total \\
\hline C & 60 & 12 & 720 \\
\hline $\mathrm{H}$ & 122 & 1 & 122 \\
\hline N & 20 & 14 & 280 \\
\hline O & 16 & 16 & 256 \\
\hline S & 2 & 32 & 64 \\
\hline \multicolumn{3}{|c|}{ Massa nominal: } & 1.442 \\
\hline
\end{tabular}

*Adaptado de Wang et al.[11].

mass). Isto evitaria a enorme confusão existente na literatura com o termo massa acurada (accurate mass), referente à relação massa/carga, $\mathrm{m} / \mathrm{z}$, medida experimentalmente em um espectrômetro de massas, usualmente com aproximação de três ou quatro casas decimais, e que seria melhor denominado pela expressão massa exata medida (measured exact mass). Como na língua portuguesa o termo acurácia (accuracy) praticamente não é empregado*, o termo exatidão (exact) tem sido usado em seu lugar, gerando alguma confusão. O emprego dos termos massa exata calculada (calculated exact mass) para o cálculo de massas a partir dos valores conhecidos das massas dos isótopos de cada elemento e dos termos massa exata medida (measured exact mass) para a massa determinada experimentalmente minimizaria as confusões da terminologia, principalmente na língua portuguesa.

* De acordo com Carlos Rocha (http://www.ciberduvidas. com, acessado em: 20 ago de 2013] "acurácia é, de fato, um termo decalcado do inglês accuracy, sendo aplicado nos domínios da física e da matemática (Grande Dicionário da Língua Portuguesa, 2004). Trata-se de um estrangeirismo que pode ser subtituído por exatidão. Curiosamente, a palavra inglesa accurate tem origem latina e é a base da formação do substantivo accuracy. Enquanto em inglês essas palavras são comuns, o mesmo não se passa em português".
Alternativamente, poder-se-ia utilizar o termo massa acurada (accurate mass) para a quantidade experimentalmente determinada e massa exata (exact mass) para a calculada, simplificando a terminologia e evitando-se confusões desnecessárias.

Durante anos, a espectrometria de massas se referiu à massa nominal de uma molécula como sendo seu peso molecular (molecular weight). A partir do emprego dessa técnica na análise de moléculas maiores que 500 u (ou u.m.a., unidades de massa atômica, à vezes também referida como Dalton, $\mathrm{Da}$ ), o conceito de defeito de massa se tornou importante ${ }^{[35]}$.

O defeito de massa é definido como a diferença entre a massa inteira e a massa exata de um átomo, molécula, íon ou radical. No caso do átomo de hidrogênio, por exemplo, o defeito de massa de 0,007825 u pode ser significativo para moléculas grandes. No caso de um alcano $\mathrm{C}_{50} \mathrm{H}_{102}$, a massa nominal do íon molecular será 702 u mas, devido ao defeito de massa do átomo de hidrogênio, a massa exata do íon será 702,7982 u, o que será observado em m/z 703 em um espectrômetro de massas de resolução unitária (quadrupolos, por exemplo). Isso significa que nesse caso a massa nominal $(702 \mathrm{u})$ e a massa inteira do mesmo íon (703 u) serão diferentes ${ }^{[35]}$.

\section{Importância da resolução e das massas exatas}

A acurácia de massas é um parâmetro importante de um espectrômetro de massas e determina a especificidade da medida de massa efetuada $^{[36]}$. A definição mais comumente empregada atualmente para acurácia de massas leva em consideração a diferença entre a massa exata (teórica) e a massa medida (acurada) em relação à massa teórica, expressa em ppm (partes por 
milhão). Entretanto, como essa é uma unidade relativa, pode variar significativamente com a massa do íon em análise.

O cálculo do erro (definido como a diferença entre o valor medido e o valor teórico) ou acurácia é usualmente efetuado da seguinte forma:

- em Dalton $(\mathrm{Da}): \Delta m_{i}=\left(m_{i}-m_{a}\right)$

- em mili Dalton $(\mathrm{mDa}): \Delta m_{i}=\left(m_{i}-m_{a}\right) \times 10^{3}$

- em ppm: $\Delta m_{i}=\frac{\left(m_{i}-m_{a}\right)}{m_{a}} \times 10^{6}$

onde $\Delta \mathrm{m}_{\mathrm{i}}$ é o erro determinado, podendo ser expresso em ppm (partes por milhão); Da, Dalton; $\mathrm{mDa}$, mili Dalton ou milésima parte de um Dalton; $\mathrm{m}_{\mathrm{i}}$, a massa exata do íon; e $\mathrm{m}_{\mathrm{a}}$, $\mathrm{a}$ massa medida.

Para um íon de massa exata 1.000 e massa medida $1.000,0025$, a diferença de massa $\Delta \mathrm{m}_{\mathrm{i}}$ será a seguinte nas diferentes unidades:

- em ppm: $(1.000-1.0025) / 10^{6}=2,5 \mathrm{ppm}$;

- em Da:0,0025 Da;

- em mDa:2,5 mDa.

Para um outro íon de massa exata 500 e massa medida 500,0025, a diferença de massa será:

- em ppm: $(500-500,0025) / 10^{6}=5$ ppm;

- em Da:0,0025 Da;

- em mDa:2,5 mDa.

Portanto, em ambos os casos, o erro determinado será o mesmo em $\mathrm{Da}$ ou em $\mathrm{mDa}$, porém diferente empregando-se ppm como unidade relativa de medida do erro. Portanto, como a acurácia de massas em ppm trata de uma unidade relativa e sujeita a variações de acordo com a massa do íon em questão, é preferível o emprego da acurácia de massas em $\mathrm{mDa}$, que reflete a medida absoluta do desempenho do equipamento.

A Tabela 4 ilustra um exemplo da determinação da acurácia da medida de um íon de massa exata 400 empregando as duas formas de expressão (ppm e mDa). Observa-se que tanto valores positivos quanto negativos podem ser obtidos, dependendo do valor experimentalmente medido ser inferior ou superior ao valor teórico calculado. Nota-se, também, que a terceira medida apresenta um erro numérico superior às outras duas.

Quanto menor o valor do erro de massas medido, ou a inacurácia da medida, mais o resultado experimental obtido se aproximará do valor teórico esperado e, portanto, mais segura será a determinação da identidade da espécie em análise. Para a obtenção de boa acurácia na determinação das massas geralmente é necessário um espectrômetro de massas de alta resolução, pois interferentes da amostra em análise podem comprometer a acurácia das medidas efetuadas ${ }^{[37,38]}$. Apesar de valores de erros da ordem de 5 ppm serem usualmente aceitos na determinação de uma composição elemental definitiva, equipamentos mais modernos, empregando analisado-

Tabela 4 Exemplo dos valores de acurácia envolvidos na determinação experimental de um íon de massa exata 400 empregando as unidades ppm, mDa e Da.

\begin{tabular}{cccccc}
\hline Medida & $\begin{array}{c}\text { Valor exato } \\
\text { (teórico) }\end{array}$ & $\begin{array}{c}\text { Valor medido } \\
\text { (experimental) }\end{array}$ & $\Delta \mathrm{m}(\mathrm{Da})$ & $\Delta \mathrm{m}(\mathrm{mDa})$ & $\Delta \mathrm{m}(\mathrm{ppm})$ \\
\hline 1 & 400,0000 & 400,0013 & 0,0013 & 1,3 & 3,3 \\
2 & 400,0000 & 399,9987 & $-0,0013$ & $-1,3$ & $-3,3$ \\
3 & 400,0000 & 400,0072 & 0,0072 & 7,2 & 18 \\
\hline
\end{tabular}


res de massas de alta (ToF) e altíssima resolução (FT-MS), apresentam rotineiramente erros inferiores a esse valor.

\section{Conclusões}

Neste artigo, segundo de uma série a respeito do acoplamento entre cromatografia líquida e espectrometria de massas (LC-MS), o foco foi o analisador de massas, que é responsável pela resolução de massas do sistema. Quando o objetivo da análise por LC-MS é a identificação da espécie eluida do sistema HPLC pelo MS, esse último deve apresentar a maior acurácia (menor erro) possível na medida das massas. Idealmente, erros ao redor de 2 ppm ou menos são desejáveis na atualidade com os equipamentos comercialmente disponíveis. Considerando-se a complexidade das amostras usualmente analisadas por LC-MS(/MS), inclusive resíduos de drogas veterinárias em tecidos, leite, ovos, mel e outras matrizes; resíduos de pesticidas em verduras, legumes e frutas; petrolômica, proteômica; metabolômica; lipodômica; glicoproteômica; e outras áreas $^{[39-48]}$, a acurácia desejada requer o uso de espectrômetros de massas de alta resolução, ou seja, daqueles que possuem analisadores de massas de alta resolução (como o ToF) ou altíssima resolução, nos parâmetros atuais, como o FT-Orbitrap e o FT-ICR. Debates em andamento na área de segurança alimentar (por exemplo, na análise de resíduos e contaminantes em alimentos de origem animal e vegetal), especialmente na Comunidade Européia (CE), sugerem para o futuro próximo a adoção da espectrometria de massas de alta resolução como padrão para a geração de dados por laboratórios acreditados/credenciados/recomendados por ela nessa área. A discussão apenas começou, mas promete muito.

\section{Agradecimentos}

$\mathrm{O}$ autor agradece ao $\mathrm{CNPq}$, à FAPESP e à FINEP/MAPA/MCT pelo apoio às pesquisas desenvolvidas no laboratório sob sua coordenação.

\section{Referências}

1 Lanças FM. A Cromatografia Líquida Moderna e a Espectrometria de Massas: finalmente "compatíveis"? Scientia Chromatographica 2009; 1(2): 35-61.

2 Brunnee C. The ideal mass analyzer: Fact or fiction? International Journal of Mass Spectrometry and Ion Processes 1987; 76:125-237. http://dx.doi. org/10.1016/0168-1176(87)80030-7

3 Thomson JJ. Philosophical Magazine 1911; 20(6):752-67.

$4 \quad$ Stephens WE. Physical Review 1946; 69:691.

5 Stephens WE. Bulletin of the American Physical Society 1946; 21:22.

6 Studt T. Chromatography Techniques. 2008.

7 Mamyrin BA, Karataev VI, Shmikk DV, Zagulin VA. The mass-reflectron, a new nonmagnetic time-offlight mass spectrometer with high resolution. Soviet Physics - JETP 1973; 37:45.

8 Mamyrin BA. Time-of-flight mass spectrometry (concepts, achievements, and prospects). International Journal of Mass Spectrometry2001; 206(3):251-266. http://dx.doi.org/10.1016/S1387-3806(00)00392-4

9 Cotter R. The curved-field reflectron: PSD and CID without scanning, stepping or lifting. International Journal of Mass Spectrometry 2005; 240:169. http:// dx.doi.org/10.1016/j.ijms.2004.09.022

10 Flensburg J, Haid D, Blomberg J, Bielawski J, Ivansson D. Journal of Biochemical and Biophysical Methods 2004; 60(3):319-34. PMid:15345299.

11 Wang T-I, Chu C-W, Hung H-M, Kuo G-S, Han C-C. Design parameters of dual-stage ion reflectrons. Review of Scientific Instruments 1994; 65:1585. http:// dx.doi.org/10.1063/1.1144896

12 Comisarow MB, Marshall AG. Fourier transform ion cyclotron resonance spectroscopy. Chemical Physics Letters 1974; 25:282-3. http://dx.doi. org/10.1016/0009-2614(74)89137-2

13 Hipple JA, Sommer H, Thomas HA. A Precise Method of Determining the Faraday by Magnetic Resonance. 
Physical Review, 1949; 76:1877-8. http://dx.doi. org/10.1103/PhysRev.76.1877.2

Marshall AG. Milestones in fourier transform ion cyclotron resonance mass spectrometry technique development. International Journal of Mass Spectrometry 2000; 200:331-356. http://dx.doi. org/10.1016/S1387-3806(00)00324-9

15 Kingdon KH. A Method for the Neutralization of Electron Space Charge by Positive Ionization at Very Low Gas Pressures. Physical Review 1923; 21(4):40818. http://dx.doi.org/10.1103/PhysRev.21.408

16 Korsunskii MI, Basakutsa VA. Soviet Physics - Technical Physics 1958; 3:1396.

17 Knight RD. Storage of ions from laser-produced plasmas. Applied Physics Letters 1981; 38:221-4. http:// dx.doi.org/10.1063/1.92315

Makarov A. Electrostatic axially harmonic orbital trapping: a high-performance technique of mass analysis. Analytical Chemistry 2000; 72:1156-1162. PMid:10740853. http://dx.doi.org/10.1021/ac991131p

19 Makarov A. Mass Spectrometer. Patent no. US 5886346; March 231999.

20 Makarov A, Denisov E, Kholomeev A, Balschun W, Lange O, Strupat K, et al. Performance evaluation of a hybrid linear ion trap/orbitrap mass spectrometer. Analytical Chemistry 2006; 78:2113-2120. PMid:16579588. http://dx.doi.org/10.1021/ac0518811

21 Makarov A, Denisov E, Lange O, Horning S. Dynamic range of mass accuracy in LTQ Orbitrap hybrid mass spectrometer. Journal of the American Society for Mass Spectrometry 2006; 17:977-982. PMid:16750636. http://dx.doi.org/10.1016/j.jasms.2006.03.006

22 Scigelova M, Makarov A. Orbitrap mass analyzer - overview and applications in proteomics. Proteomics 2006; 6:16-21. PMid:17031791. http:// dx.doi.org/10.1002/pmic.200600528

$23 \mathrm{Hu}$ Q, Noll RJ, Li H, Makarov A, Hardman M, Cooks RG. The Orbitrap: a new mass spectrometer. Journal of Mass Spectrometry 2005; 40:430-443. PMid:15838939. http://dx.doi.org/10.1002/jms.856

24 Perry RH, Cooks RG, Noll RJ. Orbitrap mass spectrometry: instrumentation, ion motion and applications. Mass Spectrometry Reviews 2008; 27:661699. PMid:18683895. http://dx.doi.org/10.1002/ mas.20186

25 Olsen JV, Godoy LM, Li G, Macek B, Mortensen $\mathrm{P}$, Pesch R, et al. Parts per million mass accuracy on an Orbitrap mass spectrometer via lock mass injection into a C-trap. Molecular \& Cellular
Proteomics 2005; 4:2010-2021. PMid:16249172. http:// dx.doi.org/10.1074/mcp.T500030-MCP200

26 Olsen JV, Macek B, Lange O, Makarov A, Horning S, Mann M. Higher-energy C-trap dissociation for peptide modification analysis. Nature Methods 2007; 4:709-712. PMid:17721543. http:// dx.doi.org/10.1038/nmeth 1060

27 Eiceman G A, Karpas Z. Ion mobility spectrometry. Boca Raton: CRC Press; 2005. http://dx.doi. org/10.1201/9781420038972

28 Sparkman DO. Mass Spectrometry Desk Reference. Pittsburgh: Global View Pub, 2006.

29 Fiehn laboratory. [cited 2013 Jan 20]. Available from: http://fiehnlab.ucdavis.edu/Seven_Golden_Rules/ Mass_Resolution.

30 School of Chemistry and Biochemistry. [cited 2013 Feb. 12]. Available from: http:ww2.chemistry.gatech. edu/ bostwick/stms/resolve.txt.

31 Murray KK, Boyd RK, Eberlin MN, Langley GJ, Li L, Naito Y. Definitions of terms relating to mass spectrometry (IUPAC Recommendations 2013). Pure and Applied Chemistry 2013; 85:1515-1609. http:// dx.doi.org/10.1351/PAC-REC-06-04-06

32 Kellman M, Wieghaus A, Muenster H, Taylor L, Glosh D. Current Trends in Mass Spectrometry 2009; 38-43.

33 Siuzdak G. The Expanding Role of Mass Spectrometry in Biotechnology. 2nd ed. MCC Press; 2006.

34 McLafferty FW, Turecek F. Interpretation of Mass Spectra. 4th ed. Sausalito: University Science Books, 1993.

35 Sparkman D. Confusion Resulting from Molecular Weight and the Nominal Mass. MS Solutions 2012; 8.

36 Brenton AG, Godfrey AR. Accurate mass measurement: terminology and treatment of data. Journal of the American Society for Mass Spectrometry 2010; 21:1821-1835. PMid:20650651. http://dx.doi.org/10.1016/j.jasms.2010.06.006

37 Webb K, Bristow ATW, Sargent M, Stein BK. Best Practice Guide: Methodology for Accurate Mass Measurement of Small Molecules. London: LGC Ltd.; 2004.

38 Barwick V, Langley JG, Mallet AI, Stein BK, Webb K. Best Practice Guide for Generating Mass Spectra. London: LGC Ltd.; 2006. PMCid:PMC1636678.

39 Bateman K, Castro-Perez J, Wrona M, Shockor JP, Yu $\mathrm{K}$, Oballa R, et al. MS ${ }^{\mathrm{E}}$ with mass defect filtering for in vitro and in vivo metabolite identification. Rapid Communications in Mass Spectrometry 2007; 21:1485- 
1496. PMid:17394128. http://dx.doi.org/10.1002/ rcm.2996

40 Tiller PR, Yu S, Bateman K, Castro-Perez J, Mcintosh I.S, Kuo Y, et al. Fractional mass filtering as a means to assess circulating metabolites in early human clinical studies. Rapid Communications in Mass Spectrometry 2008; 22:3510-3516. PMid:18853407. http://dx.doi.org/10.1002/rcm.3758

41 Tiller PR, Yu S, Castro-Perez J, Filgrove KL, Baillie TA. High-throughput, accurate mass liquid chromatography/tandem mass spectrometry on a quadrupole time-of-flight system as a 'first-line' approach for metabolite identification studies. Rapid Communications in Mass Spectrometry 2008; 22:10531061. PMid:18327855. http://dx.doi.org/10.1002/ rcm.3472

42 Zhang H, Zhang D, Ray K, Zhu M. Mass defect filter technique and its applications to drug metabolite identification by high-resolution mass spectrometry. Journal of Mass Spectrometry 2009; 44:999-1016. PMid:19598168. http://dx.doi.org/10.1002/jms.1610

43 Zhu M, Li M, Zhang D, Ray K, Zhao W, Humphreys WG, et al. Detection and Characterization of Metabolites in Biological Matrices Using Mass Defect Filtering of Liquid Chromatography/High Resolution Mass Spectrometry Data. Drug Metabolism and
Disposition 2006; 34:1722-33. PMid:16815965. http:// dx.doi.org/10.1124/dmd.106.009241

44 Zhang H, Zhu M, Ray KL, Ma L, Zhang D. Mass defect profiles of biological matrices and the general applicability of mass defect filtering for metabolite detection. Rapid Communications in Mass Spectrometry 2008; 22:2082-8. PMid:18512844. http:// dx.doi.org/10.1002/rcm.3585

45 Chowdhury SK, editor. Identification and Quantification of Drugs, Metabolites and Metabolizing Enzymes by LC-MS. In: Progress in Pharmaceutical and Biomedical Analysis; 2005; Amsterdam. Amsterdam: Elsevier; 2005. v. 6. PMCid:PMC1389856.

46 Staack RF, Hopfgartner G. New analytical strategies in studying drug metabolism. Analytical and Bioanalytical Chemistry 2007; 388:1365-80. PMid:17583803. http:// dx.doi.org/10.1007/s00216-007-1367-z

47 Prakash C, Shaffer CL, Nedderman A. Analytical strategies for identifying drug metabolites. Mass Spectrometry Reviews 2007; 26:340-69. PMid:17405144. http://dx.doi.org/10.1002/mas.20128

48 Ma S, Subramanian R. Detecting and characterizing reactive metabolites by liquid chromatography/ tandem mass spectrometry. Journal of Mass Spectrometry 2006; 41:1121-39. PMid:16967439. http://dx.doi.org/10.1002/jms.1098 